\title{
Assessment of the state of millets farming in India
}

\begin{abstract}
With nearly 60 percent of India's cultivated area is rain-fed, the damage caused by climate change is huge in agriculture sector. In order to save the farmers from such calamities, climate smart agricultural practices are increasingly promoted by government and other stakeholders. Millets cultivation is one such practice which seems to be the answer tofighting climate change, poverty and malnutrition. In this context, this paper presents briefly about India's shifting approach from paddy and wheat based farming towards millets farming. It also narrates various measures that the government and other stakeholders have undertaken particularly in the last decade to promote millets farming in India.
\end{abstract}

Keywords: millets, climate change, nutrition, India, farming, consultative, stakeholders
Volume 2 Issue I - 2017

\author{
Manoj Kumar Behera \\ NR Management Consultants India Pvt. Ltd, India
}

Correspondence: Manoj Kumar Behera, Kalinga Nagar,

Bhubaneswar-75I003, Odisha, India,

Email manojbeheral991@gmail.com

Received: October 28, 2016 | Published: March 03, 2017

\section{Introduction}

Rainfed farming which covers approximately 60 percent of the total farming area in the country contributes $44 \%$ of the total food grain production of the country, produces $75 \%$ of pulses and more than $90 \%$ of sorghum, millet and groundnut from arid and semi-arid regions. ${ }^{1}$ Millets are traditionally being grown in rainfed conditions especially by the marginal farmers and tribals. Millets are among the oldest cultivated crops in India and rest of the world. Millets comprise two main groups of species, major millets includes Sorghum and pearl millets and the minor millets are represented by six cultivated species viz. Little millets, Indian barnyard millets, Kodo millet, Foxtail millets, Finger millets, Proso millet. Nearly 60 million acres of land in India are under millet cultivation. ${ }^{2}$ India is the largest producer of sorghum and millets, accounting for over $80 \%$ of Asia's production. ${ }^{3}$

In the last few decades, India has evinced a sharp decline in the area under millets due to several factors. The decrease in cultivated area is about $80 \%$ for small millets, $46 \%$ for finger millet, $59 \%$ for sorghum, and $23 \%$ for pearl millet. The production of small millets has also decreased significantly from 56.24 in 1960 to 30.52 in 2010, 4,5 the father of Green Revolution in India has opined that state policies related to crop loan, subsidies, favourable conditions for commercial agriculture, supply of food items like rice, wheat, maida and rava at reasonable cost through the public distribution system (PDS), have shaped the minds of people to neglect minor millets. The food policies pursued over the years have pushed many people away from millets despite it being more nutritious than rice and wheat. ${ }^{6}$ The approach of selective utilisation of crops and varieties have reportedly threatened agro biodiversity leading to rapid erosion of natural resources and consequently affecting the nutritional security of people. ${ }^{7}$

It is the impacts of climate change for which the so far unrecognised millets have received a fair recognition. Global bodies are pushing millets farming with the idea that it reduces agriculture's carbon footprint while ensuring food and nutritional security. In India and other parts of the world, a growing number of farmers are switching to millets cultivation. The Consultative Group on International Agriculture Research (CGIAR) has suggested that millets are the way forward for countries like India where food security and nutrient security are a major challenge and as water-guzzling wheat and paddy will face tough challenges with temperatures increase due to global warming. CGIAR has estimated that the global production of wheat, rice and maize could decrease by 13 to 20 percent in the coming decades because of climate change. Global agricultural production will have to battle against this loss, even as production needs to rise by an estimated 70 percent to feed the 9 billion people by 2050 . In that context, it is noteworthy to mention that against a fluctuating productivity trend in case of major food crops, millets have shown exceptional increase in productivity over the last five decades. ${ }^{4}$ As India's agriculture suffers hugely from the vagaries of monsoon, millets which are also known as "famine reserves" for their prolonged and easy storability under ordinary are of great relevance. ${ }^{8}$ They are most suitable for mixed and intercropping, thus offer sustainable resources use, food and livelihood security to farmers. Additionally, given the fact that millets are very good source of nutrients, developing countries like India which reports dramatic rates of malnutrition (around one fifth of the population) particularly among children and women, promotion of millets farming can help in fighting malnutrition. The 2014 National Council of Applied Economic Research (NCAER) report has revealed the exponential drop in the consumption of hardy millets from $32.9 \mathrm{~kg}$ in 1960 to $4.2 \mathrm{~kg}$ in 2010 since urbanisation made Indians switch to wheat and rice. Cultivated as dual-purpose crops (food \& fodder), millets contribute to the economic efficiency of farming and provide food/livelihood security to millions of households, particularly the small/marginal farmers and the inhabitants of rain fed/remote tribal regions. Research says that a $1 \%$ productivity increase could reduce poverty by $0.65 \%$ (National Centre for Agricultural Economics and Policy Research Report, 2011). Increasing productivity is more important in rain fed areas as these are $30 \%$ less productive than irrigated areas. It seems that millets could be the answer to fighting climate change, poverty and malnutrition.

\section{Discussion}

\section{Importance of millets cultivation}

The promotion of millets farming merits attention, particularly from the following perspectives;

From farming perspective: Millets probably provides the best 
option to the farmers for achieving the triple objectives of farming i.e profitability, adaptability and sustainability. The millets based farming systems have the following advantages;

i. Millets are highly tolerant to increased temperatures, droughts and floods. Millets can be cultivated well in dry zones/rain-fed areas under marginal conditions of soil fertility and moisture. These are grown in the sand dunes of Rajasthan.

Water requirement is very less as compared to other crops due to an efficient root system. For example, pearl and finger millet can make do with $28 \%$ of paddy's rainfall needs. Figure 1 illustrates a comparative picture on water requirement by various cereal;

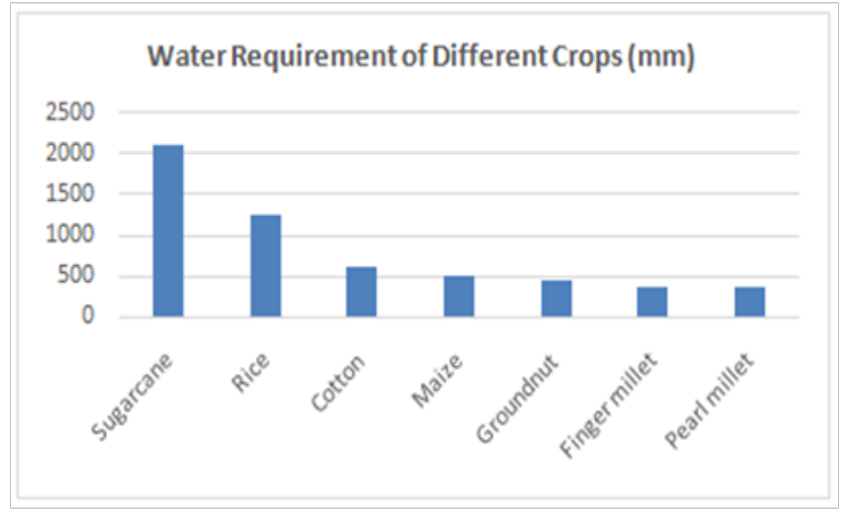

Figure I Water requirement of different crops.

The short rotation (65 days) characteristic of the millets is of vital importance to meet the food demand, especially in the highly populated regions.

Storage life is comparatively high (two years or beyond).

Millets farming requires a small investment

Inputs added are mostly organic.

Millets produce more tillers or branches than other crops.

They provide both food and fodder.

\section{From human nutrition perspective}

i. Millets are rich source of nutrients. A regular consumption can help to overcome malnutrition among majority of our Indian population. Research has established the following nutritional contributions of millets;

ii. Millets are richer in calcium, iron, beta-carotene etc. than rice and wheat.

iii. Millets are rich in dietary fibre, which is negligible in rice. Jowar has 8 times more fibre, ragi has 40 times more calcium and bajra has 8 times more iron and 5 times more both riboflavin and folic acid than rice. ${ }^{9}$

iv. Millets help check diabetes, improves digestive system, reduces cancer risk and strengthen the immune system.

v. With no gluten and low glycaemic index, millet diet is ideal for those with celiac diseases and diabetes.

vi. Minor millets has the potential to tackle iron deficiency and infertility problems (as per Nutritionist Dr Swarna Vyas ${ }^{1}$ )

vii. Millets contain high amounts of lecithin are useful for strengthening the nervous system.

viii. Millets are comparatively richer in minerals and fibres (Figures 2 \& Figure 3).

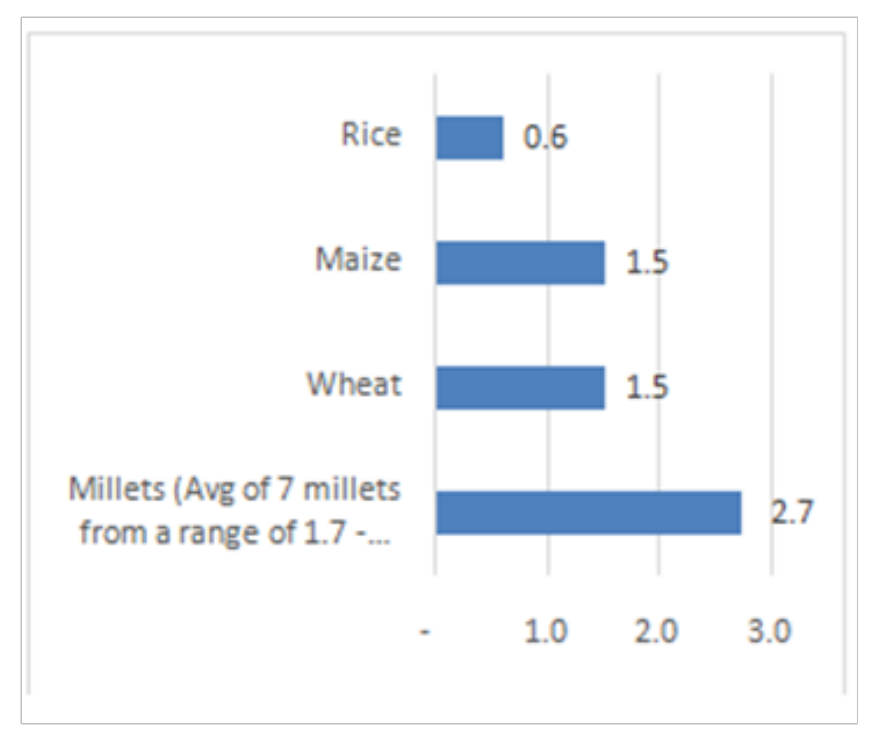

Figure 2 Minerals content in $100 \mathrm{gm}$ of cereals.

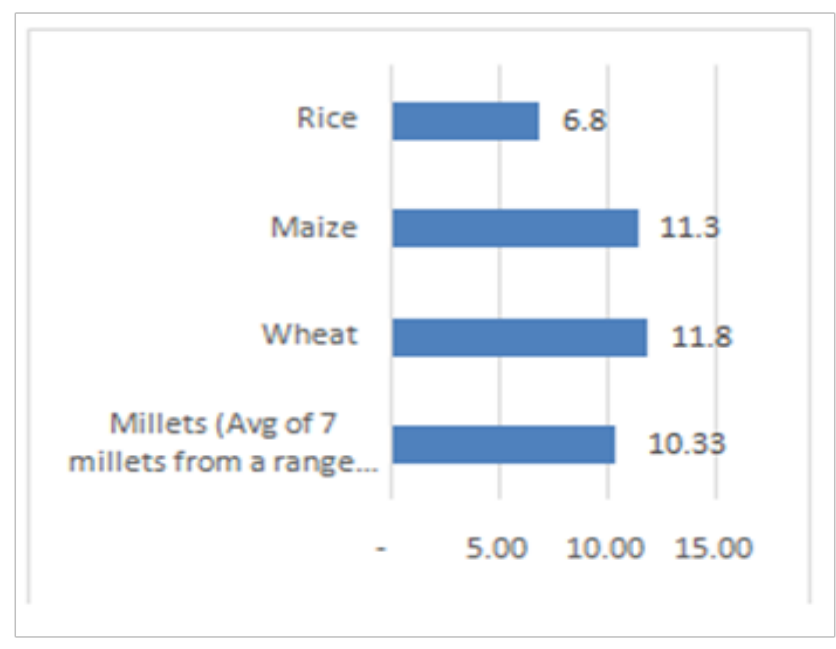

Figure 3 Protein content in 100gm of cereals.

\section{From environmental perspective}

The added advantage of millets cultivation is that it takes into account the concerns of soil and water pollution and climate change.

i. The millets don't need synthetic fertilizers or pesticide and mostly grown with organic inputs. The fact that millets are less affected by diseases and pests thus keeps pesticides at bay.

ii. Millets help in reducing the atmospheric $\mathrm{CO}_{2}$ and thus contribute in mitigating the climate change. They have a good ability to

${ }^{1}$ Millets important source of nutrition: expertsPress Trust of India | Bhopal May 24, 2016 
sequester carbon and so help climate adaptation, particularly the global projection of increased methane emission from rice fields.

\section{Millets and tribal agriculture: understanding the connections}

The tribal communities in India have a unique connection with millets. Millets have been an integral component in their farming systems and the agricultural operations. For example, Soligas, a tribe of BR Hills in Chamarajanagar district of Karnataka celebrate Ragi Habba (Festival) with harvesting of millets. ${ }^{10}$ Similarly, for most tribals of Madhya Pradesh minor millets of "Kodo" and "Kutaki" have been the largest grown single crop and which form the staple food (Gautam et al, No Year). Patil et al. (2015) have established the role of tribals in conservation of millets. According to a study undertaken by them, millets contributes 50 percent of total germplasms conserved by tribes of Nandurbar district of Maharashtra (Figure 4).Millets find an array of uses among the tribals. Sahu and Sharma have documented the medicinal and other uses of small millets by the tribals of Bastar Plateau Zone of Chhatisgarh, India. As per their study, millets were used for strengthening of mud walls, as fertilizer for onion fields, diseases and insect-pest control, protecting pulses in storage, for baking of earthen pots, treatment of animals and poultry, raising milk productivity in cattle, treatment of burns, etc. and many more uses. The other uses of small millets included, use as snacks, green fodder, medicinal uses, useful in diabetes for lowering of blood sugar, nutritionally superior to other fine cereals, and many more. The Green revolution has also affected tribal agriculture in India. The traditional approach of tribals towards farming and land use has changed a lot mostly due to the influence of state policies which undoubtedly promoted cultivation of selective crops like paddy and wheat. Basavaraj et al. has reported an average decline of $14 \%$ in millets cultivation especially from the traditional farming systems.

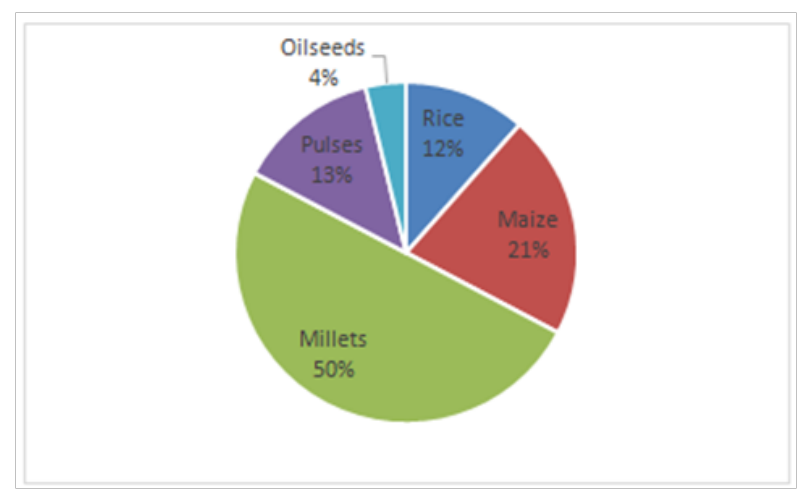

Figure 4 Germplasm conservation by tribes of Nandurbar district of Maharashtra.

\section{Does millets cultivation make a difference?}

There are plenty of evidences available in the country to show how millets farming is helping the farmers to cope with the changing situations. Table 1 presents some such evidences around that in India.

\section{Government/civil society initiatives}

\section{Initiatives of Government of India (Gol)}

Government of India has launched a number of programmes to promote millets farming, particularly in the last decade. i. Of the existing schemes, themost important ones are Initiative for Nutritional Security through Intensive MilletsPromotion (INSIMP) as part of Rashtriya Krishi Vikas Yojana” (RKVY), Rainfed AreaDevelopment Programme (RADP) as part of Rashtriya Krishi Vikas Yojana" (RKVY), andIntegrated Cereals Development Programmes in Coarse Cereals based Cropping SystemsAreas (ICDP-CC) under Macro Management of Agriculture(MMA). ${ }^{11}$

ii. Initiative for Nutritional Security through Intensive Millet Promotion (INSIMP)is the only comprehensive initiative to support millet production. Launched in 2011-12, it extensively promotes millets as "nutri-cereals". The scheme aims to catalyse increased production of millets in the country and enhancing India's nutritional security. The scheme proposed to bring 0.5 million hectares (ha) under millet cultivation and has made provision to supply hybrid seeds to the farmers. It has also proposed to establish composite millet processing centres, costing Rs 4,00,000, that handle de-stoning, de-hulling, flaking and rava- making, across the country. In the initial phase of implementation, the scheme has been criticized by civil society groups on the ground that it is trying to promote intensive mono-cropping of millets, which may defeat the purpose of millets farming. In light of this, Government of India needs to revisit the initiative and make necessary changes to encourage traditional approach of mixed-farming systems, following organic practices. ${ }^{12}$

iii. Government of India has extended to include coarse grains, such as millets, at Rs 1 per kg through the PDS under the National Food Security Bill in 2013, prior to which only wheat and rice were there in the PDS basket, which resulted in lower the consumption of coarse grains. ${ }^{13}$

\section{State led initiatives}

A few states have taken exemplary initiatives to improve both production and consumption of millets.

i. In Kerala, the Agriculture Department is implementing a mega millet cultivation drive in the backward region with the active involvement of the local community of Attappady. The programmes with an initial outlay of Rs 1.8 crore propose to cover all the 192 tribal settlements in the region. ${ }^{14}$

ii. Odisha has taken measures to implement a millet mission in 2016 to promote farming of millets and to increase production of cereal crops. The government also plans to provide market linkage to millet farmers.

iii. In Maharashtra, the government has already announced subsidies for millets.

iv. In the consumption point of view, Karnataka has set examples for other states by selling finger millet in the south and sorghum in the northern regions through the well-established PDS networks.

\section{Civil society/other initiatives}

These are a few cases of civil society engagement in promotion of traditional millets farming in India;

M.S. Swaminathan Research Foundation (MSSRF) has been working in Kolli Hills for quite a long time to promote traditional millets farming through the women collectives. It has supported more than 35 SHGs in the Kolli Hills, with over 386 members (of whom 214 are women), in the institutionalization of the various millet operations 
including millets value chain. The SHGs have formed the Kolli Hills Agrobiodiversity Conservers' Federation (KHABCoFED), a network of self-help groups (SHG) was trained in operating mills, processing, packing and labelling. They are presently supplying twenty different products of millets to local, regional and metropolis markets. ${ }^{15}$

Table I Learnings from millets farming in India

Evidences
In Medak district of Telengana, which reports the highest number of farm suicides in the state, a particular belt
which grows millet has survived the famine in 2016 when most of the farmers who have stuck to input-intensive
crops such as sugarcane, cotton and paddy were in deep distress.

A farmer from Kogira village of Andhra Pradesh's south-western district of Ananthapuramu, after experiencing continuous fall in yields in groundnut cultivation for more than 4 decades, opted foxtail millet cultivation for the first time in 2012 and realized a gross profit of $81 \%$. Since then, his income has steadily grown.

Bahri, 2016

\begin{abstract}
Many farmers in the tribal districts of Odisha like Kandhamal and Kalandi have immensely benefited from millets cultivation particularly during the food crisis due to huge losses of paddy as a result of scanty rainfall in 2015-16. The paddy growers with very small patches left for millet crops could able to meet their food demands for the whole year through millets even after losing the whole of paddy.
\end{abstract}

Millet Network of India (MINI) is a pan India alliance of over 65 institutions that promote different varieties of millet. Over 50,000 farmers are part of the alliance that has spread its activity to Uttaranchal, Nagaland, Odisha. The Deccan Development Society (DDS) is the national convenor of this alliance. Many West African nations are pursuing the agricultural models designed by the DDS that encapsulate ecological farming, biodiversity, food and nutritional security, along with ecological security. ${ }^{16}$

In Odisha, a voluntary organisation "Nirman", with the help of Kutia Kandha community has restored twelve varieties of traditional millets which almost became extinct and conserved in seven villages in Kandhamal district involving tribal people belonging to. Guruji, a tiny-sized millet is one of these 12 millets.

In Tamil Nadu, the government along with civil society is trying to convert fallow lands into millet farms.

ICRISAT in association with HarvestPlus has introduced a biofortified, early-maturing pearl millet called Dhanashakti to address malnutrition particularly iron deficiency.

\section{Conclusion}

The small and marginal farmers in India are facing multiple problems in operating their farms, many of which are systemic and reinforced by other factors in the environment: The farming systems that we need today need to be more resilient and diversified to meet the food and nutrition demands of the nation while ensuring sustainable use of natural resources. It took so any years for the government to recognise the potentials and contributions of millets based farming systems. Though late, GoI and the state governments have taken several progressive measures during the last decade to promote millets farming on a mission mode and increase awareness among the populace particularly the urban Indians for increased consumption of millets. As a result of which, millets are gaining attention and have been prioritized to a greater extent. There are some of the possible areas of intervention for the government and other stakeholders in future.

i. As millets farming has been traditionally fitted within the multi cropping farming approach, it needs to be ensured that millets do not follow the monoculture route under the government extension programmes.

ii. Government should make provisions for incentives to encourage millets cultivation

iii. Greater thrust must be given to value additionof the millets to increase demand among the urban consumers

iv. Government and CSOs should work together to generate awareness about the benefits conferred by millets and their role in nutrition and carbon sequestration needs

v. Farm mechanisation should be equally prioritized to remove the drudgery associated with its traditional processing of millets.

\section{Acknowledgements}

None.

\section{Conflict of interest}

The author declares no conflict of interest.

\section{References}

1. Basavaraj GP, Parthasarathy Rao, Shraavya Bhagavatulaand Wasim Ahmed. Availability and utilization of pearl millet in India. Journal of SAT Agricultural Research. 2010.

2. Sateesh PV. Millets: Future of food and farming. Bhoomi; 2010. 
3. Rao P, Parthasarathy, Basavaraj G. Status and prospects of millet utilization in India and global scenario. In: Millets: Promotion for Food, Feed, Fodder, nutritional and environment security, proceedings of global consultation on millets promotion for health \& nutritional security. Society for millets research, ICAR Indian institute of millets research: Hyderabad; 2013: 197-209.

4. RESMISA. Supporting Millets in India; Policy Review \& Suggestions for Action. Prepared by DHAN Foundation and WASSAN; 2012.

5. Swaminathan MS. Government-Industry-Civil Society: Partnerships in Integral Gene Management. Ambio. 2000;2:115-121.

6. Sandeep K. Promoting millets: the wheel need not be reinvented. 2012.

7. Oliver King ED, Israel, Nambi V, Arivudai integrated approaches in small millets conservation: A Case from Kolli Hills. India MS waminathan Research Foundation. 2000.

8. Passi SJ, Jain A. MILLETS: The nutrient rich counterparts of wheat and rice. Government of India: Press Information Bureau; 2014.

9. Sahu RK, Sharma ML. Medicinal and other uses of small millets by the tribal farmers of the Bastar Plateau Zone of Chhattisgarh. Hind Agricultural Research and Training Institute. 2013;8(4):596-599.
10. Jadegowda M, Ramesh MN. Empowerment of Soliga Tribes. Leisa India: 2008. p. 13-14.

11. Bohri C. A Millets Revival Could Solve India's Malnutrition Problem. Benefit Farmers; 2016

12. Gautam RS, Kumar A, Kumar S, et al. Understanding livelihood opportunities: Mandal District Madhya Pradesh. Report Published GIZ and The livelihood school.

13. Patil S, Patil, Ketaki S, et al. Germplasm conservation of Maize, Sorghum, Millets and vegetables from Dhadgaon and Akkalkuwa tribal block of Nan durbar district, Maharashtra State. Science Research Reporter. 2015;5(2):137-146.

14. The Hindu. Smart crops getting more from less; 2016.

15. ToI. Millet cultivation can save farmers fighting drought; 2016.

16. Samuel J. Eat millets, pay less, stay healthier, save earth. India Climate Dialogue; 2016. 